\title{
REFORMA SANITARIA Y MOVIMIENTO PUERICULTOR EN LA LUCHA CONTRA LA MORTALIDAD INFANTIL EN LA CIUDAD DE PALMA DE MALLORCA (SIGLOS XIX Y XX)*
}

\author{
Joana Maria Pujadas-Mora \\ Centre d'Estudis Demográficos - Universitat Autònoma de Barcelona
}

\begin{abstract}
RESUMEN
El avanzado modelo balear de Transición Demográfica se documenta por una elevada esperanza de vida al nacer — de casi 42 años en la década de 1860 - como resultado de una baja mortalidad infantil. Con el propósito de ahondar en las razones de esta situación sanitaria privilegiada se ha analizado la influencia del Higienismo sobre el descenso de la mortalidad. Para ello se ha examinado el movimiento puericultor y la reforma sanitaria de finales del siglo XIX y primeras décadas del siglo XX. Se trata de un conjunto de actividades cuya responsabilidad fue compartida por diversos actores sociales, desde médicos, abogados e ingenieros, a monjas u otros colectivos que permite pensar en la existencia de un consenso social en la denuncia de las causas 'evitables' de enfermedad y muerte.
\end{abstract}

PALABRAS CLAVE: Higienismo. Movimiento puericultor. Reforma sanitaria. Descenso de la mortalidad. Mortalidad infantil. Siglos XIX y XX. Mallorca. Islas Baleares.

* La investigación que fundamenta este artículo se desarrolló en el marco del proyecto de investigación La acción de la Administración y de la Iglesia en el proceso de dotación de servicios públicos en España (1845-1930). Un análisis regional bajo la dirección de la Dra. Isabel Moll, de la Universitat de les Illes Balears (Universidad de las Islas Baleares). Dicha investigación, a su vez, es parte de mi tesis doctoral, Evolució de la mortalitat infantil i juvenil a la ciutat de Palma (Mallorca, 1838 - 1960) presentada en la Universitat de les Illes Balears en julio de 2009. Una primera versión de este artículo fue presentada en forma de comunicación en el seminario Salud y Ciudades en España 1880-1940. Condiciones ambientales, niveles de vida e intervenciones sanitarias organizado por el Grupo de Investigación en Historia de la Población, salud y alimentación (UAB), por el Grup Balmis d'Investigació en Salut Comunitària i Història de la Ciència (UA) y por el Grupo de Historia Económica, Instituciones y Patrimonio (UMU). 


\title{
PUBLIC HEALTH REFORM AND THE INFANT WELFARE MOVEMENT IN THE FIGHT AGAINST INFANT MORTALITY IN THE CITY OF PALMA DE MALLORCA $\left(19^{\text {th }}\right.$ AND $20^{\text {th }}$ CENTURIES)
}

\begin{abstract}
The Balearic Demographic Transition has been considered a forerunner in the Spanish context due to a high life expectancy of 42 years in the decade of 1860 , owing primarily to low infant mortality. For a more in-depth evaluation of the factors behind this exceptional health situation, we analyze the role played by Hygienism in the decline of mortality due to the Infant Welfare movement and Public Health reforms that took place at the end of the $19^{\text {th }}$ century and in the first decades of the $20^{\text {th }}$ century. Both processes were led by a variety of community stakeholders such as physicians, engineers, nuns, lawyers, as evidence of a social consensus in the condemning the so-called 'avoidable' causes of disease and death.
\end{abstract}

KEY WORDS: Hygienism. Infant Welfare movement. Public Health reforms. Decline of mortality. Infant mortality. $19^{\text {th }}-20^{\text {th }}$ centuries. Mallorca. Balearic Islands.

\section{INTRODUCCIÓN}

El modelo balear de Transición Demográfica se considera avanzado en comparación con la mayoría de provincias españolas, al presentar una elevada esperanza de vida al nacer — de casi 42 años en la década de 1860-, como resultado de una baja mortalidad infantil ${ }^{1}$. El hecho ya fue reconocido por los higienistas mallorquines de finales del siglo XIX, quienes señalaron la situación sanitaria privilegiada que se daba en la sociedad balear, como una de sus principales causas ${ }^{2}$.

1 Para una visión más detenida del tema ver: BujOSA HoMAR, F. et al. (2000), La avanzada transición demográfica en Mallorca: el caso de la mortalidad infantil. Boletín de la Asociación de Demografia Historia, XVIII (II), pp. 125-146; CABRÉ, A. (1999), El sistema català de reproducció, Barcelona, Proa; Dopico, F.; ReHER, D. S. (1998), El declive de la mortalidad en España, 1860-1930, Madrid, Asociación de Demografía Histórica; GóMEZ REDONDO, R. (1992), La mortalidad infantil española en el siglo XX, Madrid, Siglo XXI; MUÑOZ PRADAS, F. (2005), Pautas territoriales de mortalidad en la España de 1860: una reconstrucción y análisis. Revista de Demografía Histórica, 23 (2), pp. 43-78; NicOlau Nos, R. (1991), Trayectoria regionales en la transición demográfica española. En EIRAS RoEL, A. (ed.) Modelos regionales de la transición demográfica en España y Portugal, 2. Asociación de Demografía Histórica, pp. 49 - 65 y PUJADAS MORA, J. M. (2009), Evolució de la mortalitat infantil $i$ juvenil a la ciutat de Palma (Mallorca, 1838-1960), Palma, Universitat de les Illes Balears, Departament de Ciències Històriques i Teoria de les Arts.

2 Nos referimos básicamente a los trabajos de los médicos Enric Fajarnés Tur (18581934) y Emili Darder Cànaves (1895-1937) y del ingeniero de caminos Eusebi Estada Sureda (1843-1917). 
La literatura especializada sobre el tema ha planteado diversas propuestas para explicar esta situación, procedentes del marco de los factores médicosociales y de comportamiento individual, del de los factores políticos e institucionales, o del de los factores económicos y ambientales ${ }^{3}$. El presente artículo pretende ahondar en alguno de los factores citados y para ello enfoca la influencia del Higienismo sobre el descenso de la mortalidad a través del movimiento puericultor y de la reforma sanitaria de finales del siglo XIX y primeras décadas del siglo XX. Se trata de temas que se identifican con factores medicosociales, políticos e institucionales, utilizados en la lucha contra la mortalidad infantil y cuya presencia se desarrolla en la ciudad de Palma de Mallorca (capital de la provincia de las Islas Baleares).

Esta lucha contra la mortalidad durante el siglo XIX se entendió por «[...] la necesidad de frenar la pérdida de aquella forma de «riqueza nacional» que eran los obreros del mañana» ${ }^{4}$ en un Estado que en 1898 había perdido sus últimas colonias lo que hizo que se revistiera de un «Regeneracionismo» de amplio espectro ${ }^{5}$. Además este clima facilitó el proceso de formación de la especialidad médica de la Pediatría ${ }^{6}$ y de su versión social, la Puericultura. Ésta última partía de la finalidad de reglar la crianza infantil sobre todo con relación a la nutrición ${ }^{7}$ y supuso «[...] la expresión profesional de la campaña de prevención de la mortalidad infantil $\rangle^{8}$. En todo este desarrollo intervinieron los

3 Véase FRENK, J. et al (1991), Elements for a theory of the health transition en la revista Health Transition Review, 1 (1), 21-38; Bernabeu-Mestre, J. et al, Determinanti della mortalità infantile e transizione sanitaria. Una riflessione a partire dall'esperienza espagnola. En BRESCHI, M. y POZZI, L. Salute, malattia e sopravvivenza in Italia fra '800 e '900, Undine, Forum, pp, 175-193.

4 RodríGuez OCAÑA, E. (1996), Una medicina para la infancia. En LLOP, J. M. B. (ed.) Historia de la infancia en la España contemporánea, Madrid, Ministerio de Trabajo y Asuntos Sociales, Fundación German Sánchez Ruipérez, pp. 149-192, p. 149.

5 BARONA VILAR, J. L. (2007), ¿Por qué mueren los niños? El debate ideológico sobre la salud infantil en la sociedad española (1904-1939). En CAMPOS, R. et al. (eds.), Medicina, ideología e historia en España (Siglos XVI-XXI), Madrid, Consejo Superior de Investigaciones Científicas, pp. 287-299.

6 Medina Doménech, R. M.; Rodríguez Ocaña, E. (1994), Profesionalización médica y campañas sanitarias. Un proceso convergente en la medicina española del primer tercio del siglo XX. Dynamis, 14, pp. 77-94.

7 Rodríguez Ocaña, 1996 y Rodríguez Ocaña, E.; Perdiguero Gil, E. (2006), Ciencia y persuasión social en la medicalización de la infancia en España, siglos XIX-XX. Historia, ciencias, saúde-manguinhos, 13 (2), pp. 1-20.

8 RodRígueZ OCAÑA, E. (1998), La construcción de la salud infantil. Ciencia, medicina y educación en la transición sanitaria en España. Historia Contemporánea, 18, pp. 19-52, p. 24. 
cambios en las doctrinas científicas en medicina y la nueva sensibilidad política refleja en leyes sociales, además de discurrir en paralelo con desarrollos coetáneos en otros países industrializados ${ }^{9}$.

El movimiento higienista integrado por un amplio abanico de profesionales: médicos, pedagogos, ingenieros, arquitectos, enfermeras, etc. se ocupó de visibilizar la situación sanitaria convirtiendo la mortalidad infantil y las necesidades higiénicas en problemas sociales ${ }^{10}$. Para este menester, el discurso social se fomentó en la cuantificación de la mortalidad y la descripción de las malas condiciones sanitarias de la población con sus posibles soluciones ${ }^{11}$. Unas soluciones que más que considerarlas terapéuticas ${ }^{12}$, cuando se focaliza en el discurso médico, fueron dirigidas a la modificación de la conducta individual o del entorno físico. Es decir, hablaríamos de la acción social de la medicina como un concepto global de Salud Pública entendido como lo planteaba el médico Ch. Winslow ya en 1920, en un artículo publicado en Science:

9 Para más detalle ver: GiJswiJT-HofSTRA, M. (2003), Cultures of child health in Britain and the Netherlands in the twentieth century, New York, Rodopi; PALACIO LIS, I. (2003), Mujeres ignorantes, madres culpables: adoctrinamiento y divulgación materno-infantil en la primera mitad del siglo XX, València, Universitat de València; PALACIO LIS, I.; RUIZ RODRIGO, C. (2002), Redimir la inocencia: Historia, marginación infantil y educación protectora. València, Universitat de València.; Perdiguero GIL, E. (2004), Salvad al niño. Estudios sobre la protección a la infancia en la Europa mediterránea a comienzos del siglo XX, València, Seminari d'Estudis sobre la Ciència; RAMAS VARO, M. L. (2001), La protección legal de la infancia en España: orígenes y aplicación en Madrid (1900-1914), Madrid, Consejo Económico y Social de España y RODRÍGUEZ OCAÑA, E. (1998).

10 BAllester, R.; BAlaguer, E. (1995), La infancia como valor y como problema en las luchas sanitarias de principios de siglo en España. Dynamis, 15, pp. 177- 192.

11 La cuantificación de los fenómenos demográficos y epidemiológicos es parte fundamental de la denominada 'Medicina Social'. Esta cuantificación permitía establecer el valor económico y la etiología social de muchas enfermedades fruto de la Industrialización como desarrolla RODRÍGUEZ OCAÑA, E. (1987): La constitución de la medicina social como disciplina en España, 1884-1923, Madrid, Ministerio de Sanidad y Consumo. Del mismo autor y relacionado con el tema se recomienda ver: La medicina como instrumento social publicado en la revista Trabajo Social y Salud (2002, núm. 43, p. 19-36) que constituye parte del monográfico «La acción social de la medicina y la construcción del sistema sanitario en la España contemporánea».

12 Aunque deben tenerse presente las campañas de vacunación local. Ver: Dossier La vacunación antivariólica en España durante el siglo XIX. Asclepio, 56(1); CANALETA SAFONT, E. et al. (2008): De la inoculación a la vacuna: Mallorca de los siglos XVIII y XIX. En PERDIGUERO, E.; VIDAl HERNÁNDEZ, J.M. (eds.). Las vacunas: historia y actualidad, Menorca, Institut d'Estudis Menorquins, pp. 37-52. 
«[...] the science and the art of preventing disease, prolonging life, and promoting physical health and efficiency through organized community efforts for the sanitation of the environment, the control of community infections, the education of the individual in principles of personal hygiene, the organization of medical and nursing services for the early diagnosis and preventive treatment of disease, and the development of the social machinery which will ensure to every individual in the community a standard of living adequate for the maintenance of health» ${ }^{13}$.

La modificación de la conducta individual en relación a la mortalidad infantil se previno a través de la educación sanitaria ${ }^{14}$ dentro de las campañas puericultoras. Éstas incluyeron la construcción de un entramado de instituciones, bien filantrópicas bien de auspicio público, dedicadas al cuidado de la infancia, especialmente en términos de nutrición, por medio del fomento de la lactancia materna. A su vez la denuncia ambiental perseguía forjar una conciencia colectiva sobre la problemática sanitaria dirigida mayormente a las esferas públicas con potestad de actuación. Es decir, la clase médica con su discurso forjó la opinión general sobre el estado de salud de la población y dirimió que elementos debían ser modificados para mejorar su estado. El contexto de producción de este discurso supuso una plataforma estratégica para formular unos determinados postulados en detrimento de otros. Esta estrategia resultaría provechosa cuando el discurso se transformaba en aplicaciones reales. Por lo tanto, su eficacia implicaría una correlación positiva entre el pensamiento médico hegemónico y las actuaciones de la Administración pública en materia de Salud Pública. Una relación muy interesante y que se puede lanzar como hipótesis para futuros trabajos dado que nuestro objeto de estudio es analizar los anclajes estratégicos de la clase médica utilizados para construir y modelar la conciencia social en relación a la salud.

La intencionalidad social de este discurso, sobre todo del discurso médico, en la ciudad de Palma, se vehiculó básicamente a través de dos asociaciones científicas, la Real Academia de Medicina y Cirugía (1831 - actualidad) y del Colegio Médico-Farmacéutico (fundado en 1882 y precursor del actual Colegio de Médicos de Baleares) ${ }^{15}$. Por obligación estatutaria el ingreso de socios

13 WinsLOw C.E.A (1920), The Untilled Fields of Public Health. Science, 51, pp. 23-33, p. 30 .

14 La educación sanitaria puede entenderse como el «[...] suministro a la población de conocimientos médicos actualizados, es decir, algo similar a la popularización o divulgación sanitaria» (RODRÍGUEZ OCAÑA; PERDIGUERO GIL (2006), p. 305.)

15 Ver: TOMÁs Monserrat, J. (1985), Medicina y sociedad: el colegio de médicos de Baleares 1882-1982, Palma, Colegio oficial de médicos de Baleares. 
y la inauguración del año académico suponían sendas alocuciones que normalmente se publicaron como folletos o como artículos de la Revista Balear de Medicina, Farmacia y Veterinaria, órgano del colegio que apareció por primera vez en enero de 1885 y en 1888 adoptó el nombre de Revista Balear de Ciencias Médicas. Estas disertaciones tenían una clara función expositiva y argumentativa con un uso constante de términos técnicos de la Medicina dado que sus emisores y receptores eran profesionales de la salud. Aunque también pudieron tener una finalidad meramente descriptiva, sobre todo cuando el autor se limitaba a exponer la investigación de otros científicos. Tanto una finalidad como otra indican la ortodoxia de la práctica académica. Su extensión no superó las 15 páginas y siempre se escribieron en castellano.

Los materiales de divulgación sanitaria normalmente confeccionados por los mismos médicos constituyen otras fuentes de gran importancia para nuestro estudio. La temática y la forma fueron muy diversas, pero tenían una finalidad claramente didáctica dirigida a la modificación de la conducta ciudadana en relación a la salud. Su pretensión pedagógica procedía de la idea de prevención y en cierta manera capacitaba a los ciudadanos a evitar problemas de salud mediante el propio control de las situaciones de riesgo. Desde una perspectiva de promoción de la salud se procuraba, por ejemplo, combatir las prácticas populares en salud, prácticas frecuentemente propuestas con anterioridad por la propia clase médica ${ }^{16}$. Este tipo de documentos buscaba la interacción con el receptor, público en general o bien con un perfil definido como el caso de las cartillas que incluían consejos puericultores dirigidos a las madres. Las instituciones, asociaciones, etc. que promovieron este tipo de divulgación en Palma fueron varias y diversas. Desde las propias instancias públicas a asociaciones obreras o culturales, como la Associació per la Cultura de Mallorca o el Foment de la Dona durante la Dictadura de Primo de Rivera y la Segunda República. El catalán fue a menudo su lengua vehicular, a consecuencia, seguramente, de ser el idioma en que se expresaban sus destinatarios.

Para el presente artículo las fuentes citadas se tratan a partir del análisis de su contenido ${ }^{17}$. Por otra parte el sujeto de estudio se identifica con los actores

16 Perdiguero Gil, E. (1995), Popularización de la higiene en los manuales de economía doméstica en el transito de los siglos XIX al XX. En BARONA, J.L.; Micó, J. (eds.). Salut i malaltia en els municipis valencians, València, Seminari d'Estudis sobre la Ciència, pp. 225-250.

17 Para una explicación amplia y extensa sobre la investigación cualitativa y de su evolución en la literatura metodológica ver: Procediments qualitatius de recollida d'informació, i el primer capítulo: Investigació qualitativa, pp. 229-255 de BRUNTE, I. et al. (2002) Tècniques d'investigació social: fonaments epistemològics i metodològics, Barcelona, Pòrtic. Otras refe- 
responsables del movimiento higienista que actuaba en Palma de fines del ochocientos y principios del novecientos. La finalidad de este tipo de análisis consiste en observar como este tipo de actuaciones se adaptan a un contexto más general, por ejemplo las transformaciones sociales de Europa a finales del XIX y principios del $\mathrm{XX}^{18}$.

\section{LA REFORMA URBANA, UN EJEMPLO DE ACCIÓN URBANÍSTICA GUIADA POR LA OPINIÓN SANITARIA}

La clase médica mallorquina mostró las 'necesidades higiénicas' de la ciudad de Palma por medio de cálculos demográficos y epidemiológicos ${ }^{19}$. Éstos se leían desde una óptica catastrofista, lo que manifestaba un deplorable estado sanitario, lo cual justificaba su intervención. Estos médicos se encargaron de marcar las líneas de actuación para mejorar la situación sanitaria, proponiendo la actuación pública en materia de Salud Pública junto a recomendaciones de Higiene Privada ${ }^{20}$. Claro está que este discurso no tenía la infancia

rencias de gran interés: BALCELLS JUNYENT, J. (1994): La investigación social: introducción a los métodos y las técnicas, Barcelona, Promociones y Publicaciones Universitarias y BRUNET, I. et al. (2000), Les tècniques d'investigació social i la seva aplicació, Tarragona, Universitat Rovira i Virgili. Servei Lingüístic.

18 Arostegui, J. (2001), La investigación histórica: teoría y método, Barcelona, Crítica, p. 408.

19 Contrariamente los médicos mallorquines desatendieron la cuantificación de la mortalidad infantil a diferencia por ejemplo del médico catalán Lluís Comenge (1854-1916) que en 1900 publicó su estudio la Mortalidad infantil de Barcelona según las clases sociales. Para seguir el tema ver: RodRíGUEZ OCAÑA, E. (1986), La labor estadística de Luís Comenge (1854-1916) en el Instituto de Higiene Urbana de Barcelona. Dynamis, 5-6, pp. 279-306. Por su lado, la Sociedad Española de Higiene desde su constitución en 1881 entendió la correlación positiva entre la poca vitalidad del crecimiento de la población española y la alta mortalidad en la infancia. De aquí que en 1885 esta sociedad promovió el estudio del también médico Juan Aguirre y Barrio, la Mortalidad de la primera infancia. Causas y medios de atenuarla como describen Perdiguero Gil y Robles GonzÁlez (2004). La lista de este tipo de estudios podría ampliarse con algunas publicaciones más pero tampoco es nuestro objetivo revisar este tipo de producción.

20 Sobre la importancia de las actuaciones públicas en materia de Salud Pública como factor determinante del descenso de la mortalidad, véanse los trabajos de Simon Szreter. Por ejemplo: SzRETER, S. (2002a), Rethinking Mckeown: The relationship between public health and social change. American Journal of Public Health, vol. 92 (5), pp. $722-725$ y SzRETER, S. (2002b), The state of social capital: bringing back in power, politics, and history. Theory and 
como único destinatario, sino al conjunto de la población, como si veremos en el movimiento puericultor.

Esta reforma pública recibió el apelativo general de Saneamiento de Pal$m a$, tal como el médico Bernat Riera Alemany tituló 5 conferencias que pronunció en el Colegio Médico-Farmacéutico entre 1900 y 1902. Esta institución fue la plataforma que utilizó la clase médica mallorquina para plantear la reforma bajo los siguientes términos:
«La población urbana en suma, está amenazada en cuanto respecta a las condicio- nes que le dan este calificativo:
$1^{\circ}$ Por la infección del suelo y del agua.
$2^{\circ}$ Por las alteraciones comunes o específicas de la atmósfera.
$3^{\circ}$ Por la imperiosidad relativa de recursos alimenticios, y
$4^{\circ}$ Por la multiplicidad de contactos entre personas y entre personas y cosas, como dato de progresión de afectos contagiosos cuando sus gérmenes lleguen al grupo.[...]» ${ }^{21}$.

Con la utilización de la terminología médica de infección y alteración, Bernat Riera justificaba la actuación en el ámbito de la conducción de residuos, de la canalización del agua potable, de la inspección de mercados de productos alimentarios y mataderos y del sistema de limpieza de las vías públicas. Pero también se ocupaba de la esfera privada a través de la denuncia del hacinamiento en las viviendas y la ubicación de las fosas sépticas. Es decir, unieron la Higiene Pública y la Privada con la intención de que:

«[...] la profilaxis individual sería la vanguardia de la oficial, y ambas constituirían un preservativo eficaz, porque si bien la profilaxis pública es siempre menor

Society, 31, pp. 573-621. Sobre políticas municipales de reforma urbana destacaremos ver, en otros, SALAS VIVES, P. (2002), Les obres públiques a Mallorca durant el segle XIX. Consideracions sobre l'acció de l'administració pública a l'època contemporánea. Mayurca, 28, pp. 5374 por su localización geográfica aunque su base de estudio es parte de la población rural de la isla. También citar los trabajos de Josep Lluís Barona para la realidad valenciana: (2002): BARONA VILAR, J. LL. (2002), Política urbanística i higiene de les ciutats. La societat valenciana en el trànsit al segle XX. Gimbernat, 38, pp. 223-238; BARONA VILAR, J. LL. (2002), Salud, enfermedad y muerte. La sociedad valenciana entre 1833 y 1939, Valencia, Institució Alfons el Magnànim y BARONA VILAR, C. (2006), Las políticas de salud: la sanidad valenciana entre 1855 y 1936, Valencia, Universitat de València.

21 Riera Alemany, B. (1891), Estudios generales de Higiene Pública en sus relaciones con las condiciones sanitarias de Palma. Revista Balear de Ciencias Médicas, 7, pp. 225-231, p. 229. 
que la privada, los dos se complementan y hacen una profilaxis absoluta [...]. La profilaxis privada es superior a la oficial, porque no pueden responder en absoluto los Poderes públicos, aunque tengan montados a la perfección, que es mucho tener, un sistema de desinfección y saneamiento, y aunque esté la población en las mejores condiciones higiénicas imaginables» ${ }^{22}$.

Son palabras que justificaban la intervención médica en la divulgación de los preceptos higiénicos para que la sociedad palmesana se concienciara de la necesidad de una reforma sanitaria. Una concienciación que ya se venía fraguando desde hacía tiempo ya que en marzo de 1893 el Colegio MédicoFarmacéutico inició un ciclo de 13 conferencias, de las que 3 se dedicaron a la Higiene Pública de la ciudad de Palma a cargo del médico Bartomeu Bordoy Gelabert (1831-1906)23 y otras 3 tituladas de Reforma Sanitaria de Palma las impartió Joan Munar Bennàssar (1846 - 1911)24.

En este discurso sobre la reforma sanitaria de la ciudad, que sólo se ha esbozado, resalta un elemento recurrente que utilizó la clase médica mallorquina: el derribo de las murallas. Esta cuestión se puede considerar como el ejemplo paradigmático de la creación de un estado de opinión por parte de los expertos en problemas sanitarios. Un problema que fue denunciado no sólo desde el Colegio Médico-Farmacéutico sino también desde la Real Academia de Medicina y Cirugía. Aunque no por ello dejaron de oírse voces discordantes como la del médico Bartomeu Bordoy Gelabert que bajo principios miasmáticos argu-

22 Oliver Mulet, G. (1902), Disgregaciones sobre higiene, Palma, Tipografía de las hijas de Juan Colomar, p. 13-14. Gabriel Oliver Mulet (1847-1934) se doctoró en Medicina en la Universitat de Barcelona en 1871. Fue alcalde de la ciudad de Palma entre 1877 y 1878 y médico municipal entre 1919-1934. Fue académico numerario de la Real Academia de Medicina y Cirugía al igual que miembro del Colegio Médico-Farmacéutico. Colaboró activamente en la Revista Balear de Ciencias Médicas. Para más detalles ver: GRAN ENCICLOPÈDIA DE MALLORCA (1888-2004), (2), pp. 210-211 y TOMÁs MONSERRAT, J. (1985), p. 39.

23 Estudió Medicina en la Universitat de Barcelona según título expedido en Madrid el 1 de septiembre de 1854. Fue académico numerario y vicepresidente de la Real Academia de Medicina y Cirugía de Palma. Al igual que director de la revista del Colegio MédicoFarmacéutico de Palma. Sobre el médico en cuestión se recomienda ver: GRAN ENCICLOPÈDIA DE MALLORCA (1888-2004), volumen 12, p. 73 y TOMÁS MONSERRAT, J. (1985), pp. 39-40.

24 Se licenció en Medicina en la Universidad Central en 1871. Fue profesor de anatomía e higiene en la Institución Mallorquina de Enseñamiento, vicepresidente de la Sección de Ciencias del Ateneo Balear, inspector de sanidad, vicepresidente del Colegio de Médicos de Baleares y presidente de la Real Academia de Medicina y Cirugía de Palma. En 1880 fue nombrado regidor del Ayuntamiento de Palma. Para reseguir la figura ver: GRAN ENCIClOPĖDIA DE MALlORCA (1888-2004), volumen 11, pp. 244-245 y TOMÁs MONSERRAT, J. (1985), p. 40. 
mentaba la no necesidad de su derrumbe en su conferencia Higiene Pública en la ciudad de Palma publicada en 1893. El derribo no fue efectivo hasta 1902. Los argumentos de carácter sanitario esgrimidos a su favor eran higiénicos pero también demográficos dado el crecimiento de la población que la ciudad de Palma había experimentado desde finales del siglo XVIII. La ciudad de Palma en 1787 tenía poco más de 34.000 habitantes, en 1860 contaba con más de 50.000 .

Toda esta reforma sanitaria se justificó con los resultados del perfil epidemiológico de la ciudad a través de la cuantificación de la mortalidad por enfermedades como la fiebre tifoidea, una de las enfermedades consideradas evitables por su conocimiento etiológico. Destacaremos dos estudios que utilizaron dicha enfermedad como parte de su justificación discursiva. El primero de ellos se tituló Enfermedades infecciosas en la ciudad de Palma durante el invierno de 1899 un dictamen realizado en la Real Academia de Medicina y Cirugía por petición del Ayuntamiento de la ciudad con la intención de conocer las enfermedades reinantes en esta capital. Su autor fue el médico Enric Fajarnés Tur (1858-1934).25 Para establecer el perfil epidemiológico no sólo se sirvió del número de defunciones por dicha causa sino que utilizó todas aquellas acaecidas por causa infecto-contagiosa para el periodo 18801894 en un ejercicio de demostración del número de defunciones que podían evitarse. En cuanto a la fiebre tifoidea manifestaba que en el momento no revestía de gravedad pero se había convertido en una enfermedad endémica de la ciudad como consecuencia de «[...] la incuria y la ignorancia higiénicas [las cuales] han colocado la población en un estado lastimoso, que hubiera podido evitarse obrando con previsión, atendiendo los sanos consejos de la ciencia y dedicando á los servicios de policía sanitaria urbana de Palma, los cuidados que necesitan las poblaciones modernas» ${ }^{26}$. Su erradicación pasaba por el examen bacteriológico de las aguas públicas y privadas, por la desinfección del alcantarillado, por la declaración obligatoria de la enfermedad y de todas aquellas enfermedades gastrointestinales y por el aislamiento de los enfermos. Y todo ello tendría fácil cumplimiento dentro de un regla-

25 Para una aproximación a la figura de este médico ibicenco que puede ser calificado como el padre de la demografía balear a más del de la historia de la medicina ver: Enric $\mathrm{Fa}$ jarnés $i$ Tur (1858-1934) entre la demografia i la història editat per Ernest Prats y Joana Maria Pujadas publicado en Palma en 2008 por parte de la Conselleria d'Economia, Hisenda i Innovació en la colección 'La ciència a les Illes Balears'.

26 FAJARNÉS TUR, E. (1900), Enfermedades infecciosas en la ciudad de Palma durante el invierno de 1899, Palma, Imprenta de las Hijas de Juan Colomar, p. 7. 
mento de policía sanitaria urbana bajo la dirección de los médicos municipales, el cual no existía.

El segundo estudio formó parte de un compendio de cinco conferencias impartidas por el médico Bernat Riera Alemany y tituladas, como ya se ha indicado antes, Saneamiento de Palma. Su aproximación cuantitativa a partir del número de defunciones por fiebre tifoidea sirvió para establecer el número de días de trabajo perdidos en la ciudad de Palma afirmando que por culpa de la enfermedad anualmente se dejaban de percibir 12.500 jornales. También asignó un valor monetario a cada vida perdida con el propósito de mostrar que la inversión pública en materia de Salud Pública sería menos costosa que el valor de las vidas perdidas. Por esto:

«Aunque cotice modestamente en 1.000 pesetas el precio medio del palmesano y no dé a su actividad en el trabajo colectivo un valor medio superior a 3 pesetas, siempre resultará que las 300 muertes evitables que suceden al año suponen al capital colectivo una pérdida de 300.000 pesetas; que los 30 mil jornales no realizados por razón de enfermedad evitable suponen 90.000 pesetas más perdidas del propio capital, suma que puede aumentar en 40.000 pesetas más atendiendo al trabajo perdido por los enfermeros, y finalmente, que los gastos de 3.000 enfermedades que la higiene pudiera ahorrar calculados sencillamente por una mediana de 40 pesetas-cantidad poco crecida habiendo calculado a las enfermedades una duración de 10 días- formalizan otra partida de 120.000 que ha de sumarse a las anteriores, operación que da un resultado de 550.000 pesetas anuales, que precisa abonar si hemos de ser lógicos en los presupuestos que se formulen para realizar el saneamiento de esta ciudad, tan imperiosamente reclamado ${ }^{27}$.

Aunque sólo se hayan mostrado las aportaciones de la clase médica en la creación del estado de opinión sanitario balear, debe tenerse en cuenta el trabajo de los profesionales de la educación o de la ingeniería de obras públicas, como sucedió en el resto de España. Como ejemplo cabe citar al ingeniero Eusebi Estada (1843-1917), autor de una valiosísima obra, La ciudad de Palma: su industria, sus fortificaciones, sus condiciones sanitarias y su ensanche, con un apéndice sobre las condiciones que han de reunir las viviendas para ser saludables (1885), que fue constantemente citada por los médicos mallorquines y utilizada con frecuencia como piedra angular en la presentación de las necesidades higiénicas de la ciudad. Una reciprocidad entre profesionales que fue expresada por el propio Eusebi Estada de la siguiente manera:

27 Riera Alemany (1902), pp.26-27. 
«La clase médica ha respondido cumplidamente a este movimiento de la opinión y lo ha alentado con su inagotable autoridad en materias sanitarias, ya en los discursos leídos en la Academia de Medicina y colegio Médico-Farmacéutico, ya al emprender esta última corporación el estudio de la Topografía médica de Palma, ya en los artículos publicados en la Revista Balear de Ciencias Médicas sobre higiene y estadística demográfico-sanitaria, ya en fin, reconociendo explícitamente en un documento oficial publicado en el Boletín de la provincia, en el informe sobre el modo de combatir la difteria: la perniciosa influencia que sobre la salud pública ejercen las malas condiciones del alcantarillado y del abastecimiento de aguas de las poblaciones, factores importantes en la etiología de las enfermedades contagiosas» (Estada, 1885: XVI). ${ }^{28}$

Aunque desde la clase médica se oyeron voces, bastante marginales, de su supuesta prevalencia en la gestión y difusión sanitaria:

«[...] solamente los Médicos tiene la exclusiva para formular juicios científicos en todo lo relativo a la Higiene, porque las Medicina es la única Ciencia que exige en su programa oficial el aprobado de esta rama de sus estudios, para ejercerla con título y derecho profesional. Que todas las demás Ciencias, incluso la Química, caen en el intrusismo cuando emiten conclusiones higiénicas no admitidas en la enseñanza oficial de la Medicina [...] ${ }^{29}$.

\section{EL MOVIMIENTO PUERICULTOR}

\section{a. Combatir la mortalidad infantil por el fomento de la lactancia materna.}

«Amantarás a tu hijo bajo pena de ser mala madre siempre que puedas o lo juzgue así el médico de tu hijo, porque deber ineludible de toda madre es criar a tu hijo $[\ldots]\rangle^{30}$.

La nutrición infantil a lo largo del último cuarto del siglo XIX complementó el discurso que se venía manteniendo sobre los problemas higiénicos a consecuencia de la insalubridad de las viviendas, de la falta de cuidados maternos por la integración de la mujer en el mercado laboral, la de pauperiza-

28 Citado por Oliver JaUMe, J. (2002), Urbanisme, societat i educació. La construcció social de la realitat a partir de l'enderrocament de les murades de Palma (1902), Palma, IX Conferencia de Sociología de la Educación, Las reformas educativas en la España actual.

29 BORDOY GELABERT, 1893, pp. V-VI.

30 Mir MiR, J. (1906a), Cartilla higénica para los niños que debe seguir toda madre, Palma, Tipografía de las Hijas de J. Colomar, pp. 1-10, p. 1. 
ción de la clase obrera y la herencia morbosa ${ }^{31}$. Así el médico Josep Cerdà Coll pronunció el discurso inaugural del año académico de 1900 del Colegio Médico-Farmacéutico de la ciudad de Palma con el título de La necesidad de la lactancia materna. Su disertación empezaba denunciando el abandono de su práctica en la ciudad de Palma. Manifestaba que «[...] es moda ya en nuestra ciudad, el que las madres no amamanten a pequeñuelos, rompiendo uno de los preceptos del matrimonio, y arrastrando la serie de inconvenientes que lleva en pos de sí tal modo de obrar» ${ }^{32}$. Aunque no especificó detenidamente los motivos del abandono, éstos pudieron ser consecuencia de la incorporación de la mano de obra femenina al sector industrial ${ }^{33}$ o por algunos conceptos de belleza que se empezaron a difundir entre la burguesía, como el autor señalaba en su texto. También afirmaba que las mujeres que vivían en el mundo rural eran más saludables ${ }^{34} \mathrm{y}$ por lo tanto su leche era de mejor calidad dado que tenían una vida activa y laboriosa ${ }^{35}$. En el trasfondo de este discurso se percibe un tono moralizador producto de la función estipulada para la mujer de finales del siglo XIX y de buena parte del siglo XX: la función de esposa y madre.

Se observa como los facultativos mallorquines, en consonancia con los del resto del Estado, abogaron por la lactancia materna en detrimento claramente de la lactancia mercenaria y la lactancia artificial sin causa médica justificada. La lactancia natural era explicada por los beneficios que aportaba a la madre recién parida. Así, ésta servía para regularizar

«[...] los fenómenos del estado puerperal, combate la predisposición a la hemorragia uterina, disminuye los sudores puerperales, previene las erupciones que a

31 RodríGUEZ OCAÑA, E. (1996)

32 Cerdà Coll, J. (1900), Necesidad de lactancia materna, Palma, Tipografía Hijas de Juan Colomar y Salas, pp. 1-30, p. 6.

33 Para una aproximación local sobre la participación de la mujer en el mercado laboral ver: Escartín BisBal, J. M. (1997), La dona en la Mallorca contemporània, Palma, Documenta Balear o de la misma autora conjuntamente con Aina R. Serrano Espases señalar el capítulo La dona i el món de la fàbrica a Mallorca en el libro Dones a les Illes: treball, esplai $i$ ensenyament (1895-1945) publicado en 1997.

34 Sobre el estado de salud del mundo rural destacaremos el reciente artículo de GALIANA $M^{a}$ E.; BernABeu-Mestre, J. (2006), El problema sanitario de España: Saneamiento y Medio Rural en los primeros decenios del siglo XX. Asceplio, LVIII, pp. 139-164. Afirman que el estado de salud de las poblaciones rurales no era tan sano como se preveía desde las ciudades, denuncia que realizaron algunos médicos e higienistas como nos presentan los autores en este artículo.

35 Cerdà Coll, J. (1900), p. 7. 
veces se presentan, disminuye la urgencia y congestión uterina post-partum, favorece el retorno de esta víscera a sus condiciones ordinarias, y tiene, en fin, para la madre todos los caracteres de una evacuación crítica .» ${ }^{36}$.

Aparte de estas ventajas físicas también se reseñaban otras ventajas psicológicas; y por supuesto se exponía el provecho que suponía para el niño, ya que esta leche implicaba

«[...] como se producen relación con sus fuerzas digestivas, sufre modificaciones incesantes proporcionales al desarrollo progresivo de sus órganos, responde á todas sus necesidades, y está por completo en la perfecta armonía con las moléculas del organismo del niño» ${ }^{37}$. (Losada Mulet, 1907: 318).

Además era «[...] la única medicina que puede contrarrestar la mortalidad de la primera infancia $[. .$.$] y no es que dicha mortalidad sea un mito, horrori-$ $z a$ enterarse de ella, y mucho más en determinadas comarcas $»^{38}$.

La tarea del médico no se limitó exclusivamente a la explicación de los motivos por los cuales era conveniente la lactancia materna, sino también pautó su administración. Se aconsejó la cantidad de leche que debía ser suministrada a cada edad en condiciones normales de desarrollo del niño y sin la presencia de incapacidad física de la madre. Igualmente se especificó como y cuando debía ser efectuado el destete. Así, el también médico Josep Mir Mir $\left(1883\right.$ - 1939) ${ }^{39}$ en la redacción de una cartilla pedagógica de capacitación para las madres (1906) afirmaba que:

«En reglamentar las horas de las tetadas está en el secreto de la higiene infantil. Tomará tu hijo el pecho o el biberón cada dos horas, los dos primeros meses de su vida y solamente cada tres en los restantes hasta el destete, no dándole jamás más leche que la que pueda contener su estómago, pues en vez de vigorizarlo lo mata-

36 Losada Mulet, 1907, p. 317. Eugeni Losada Mulet (1860-1923). Doctor en Medicina y Cirugía en 1880. Fue médico forense e inspector del Ayuntamiento de Palma. Miembro de la Real Academia de Medicina y Cirugía. Fue alcalde de Palma entre 1897 y 1899. Para más información ver: GRAN ENCICLOPÈDIA DE MALLORCA (1988-2004), volumen 8: 136; TOMÁS MONSERRAT (1985), p. 46.

37 LOSADA MulET, E. (1907), p. 318.

38 CERDÀ COLL, J. (1900), p. 10.

39 Se licenció en Medicina en la Universitat de Barcelona en 1905. Fue médico de la Inclusa Provincial y de la Casa de la Misericordia según la Gran EnCICLOPEDIA DE MALLORCA (1988-2004), volumen 11, p. 40. 
rás. Durante la noche tomará alimento dos veces en los primeros meses y solamente una en los restantes ${ }^{40}$.

En esta misma cartilla también se regulaba la introducción de la alimentación complementaria. De esta manera: «Hasta cumplido 3 años no probará tu hijo carne, frutas, café, ni vino y nunca comerá fuera de las horas reglamentarias, no haciéndolo ni tampoco en éstas con exceso» ${ }^{41}$. Esta cartilla representa un ejemplo de material de divulgación que iba dirigido exclusivamente a las mujeres. Su finalidad era la de adoctrinarlas en la tarea de ser madres a través de un discurso en el cual el médico tenía un papel central en la crianza de los niños ${ }^{42}$. A su vez tenía la pretensión de destronar cualquier tradición popular en cuestiones de salud ${ }^{43}$.

El uso de otro tipo de lactancia sólo se justificó por el padecimiento de la sífilis o la tuberculosis o la falta de secreción láctea. De esta manera se pudo recomendar una lactancia mercenaria o artificial. Para esta última el médico Josep Cerdà (1900) en el mismo discurso anteriormente citado explicaba como el proceso de pasteurización suponía un avance importante dado que:

«[...] las doctrinas de Pasteur, que tienen a las ciencias biológicas una significación no inferior a la que tiene la luz en la vida orgánica, tanto es lo que deslumbran, tanto es lo que significan en todos los momentos de su desarrollo, han cambiado por completo la faz del problema; y hoy día, garantiendo la pureza de la leche y su esterilización, y cumpliéndose cuidadosamente algunas reglas al alcance de un mediana inteligencia y de una voluntad, la lactancia mixta es indudablemente superior a la mercenaria, y la lactancia artificial sostiene como ésta una ruda y equilibrada competencia.» ${ }^{44}$.

\footnotetext{
40 Mir MiR, J. (1906a), p. 2.

41 Mir Mir, J. (1906a), p. 7.

42 Palacio Lis, I. (2003)
}

43 Bernabeu Mestre, J. (2002), Cultura médica popular y evolución de la mortalidad: los cuidados de salud en la infancia durante la España contemporánea. Revista de Demografia Histórica, XX (II), pp. 147-162; CASTEJÓN et al. (2006), The mass media at the service of the fight against venereal diseases and the protection of maternal-infant health (1900-50). Historia, ciencias, saúde-manguinhos, 13(2), pp. 113-138 y Perdiguero Gil, E.; Bernabeu MeSTRE, J. (1997), Burlarse de lo cómico nacido de la tontería humana: El Papel otorgado a la población por la divulgación higiénico-sanitaria durante la restauración. En MONTIEL, L.; PORRAS, I. (coords.), De la culpabilización Individual a la Culpabilización de la Víctima. El papel del paciente en la prevención de la enfermedad, Madrid, Doce Calles, pp. 55-66.

44 Cerdà Coll, J. (1900), p. 30. 
Aún así Enric Alabern, médico responsable de la creación de la Gota de Leche de Maó, ${ }^{45}$ en su tesis doctoral Sobre lactancia artificial en las instituciones de puericultura y en la práctica privada, publicada en 1921, concluía que la lactancia artificial:

«[...] hay que evitar[la] en lo posible, facilitando, fomentando y hasta creando, si así puede permitirse decir, la alimentación natural y específica de los niños, hasta tal punto que en la mentada Institución de Puericultura [Gota de leche de Maó] conseguimos reunir un mayor contingente de madres lactantes que de madres secas, encareciéndoles hasta la sugestión, a unas y otras, lo peligroso de la lactancia artificial y que los biberones allí preparados con leche esterilizada de vaca no son, a pesar de su cuidadosa y atenta preparación, lo mejor que puede darse a los críos privados del pecho, como ellas, las madres, pudieran tal vez creer, sino lo menos malo que puede ofrecérseles a falta de aquel, que es lo verdaderamente mejor.» ${ }^{46}$.

Además en la tesis de Alabern también se mostraban los inconvenientes y beneficios para los niños para quienes estaba contraindicada la leche materna o esterilizada del uso de la leche animal cruda (refiriéndose casi exclusivamente a la de vaca) y de la tratada con calor. Por lo cual, el médico afirmaba que sólo las condiciones de salud del niño y de los medios técnicos disponibles eran los factores que dirimirían el uso de un tipo u otro de leche artificial. Aunque la leche esterilizada fuera» [...] hoy por hoy, la más fácilmente obtenible y el alimento más calificado de los niños sanos en lactancia artificial» ${ }^{47}$, ya que la leche cruda:

«[...] está contraindicada en la mayoría de los niños más que nada por los peligros de su manejo, si ha de mantenerse, como debe mantenerse, aséptica hasta ingestión, y luego por el disparatado precio que alcanza en las capitales donde [no] se cuenta con recursos para las costosas instalaciones de producción más los gastos del personal idóneo y suficientemente ilustrado (técnico) para hacerse cargo de lo que es el estado aséptico, sabiéndolo obtener y mantener» ${ }^{48}$.

La esterilización de la leche era la técnica más utilizada en las Gotas de Leche españolas, lo cual reforzaba su utilización dada la reducción de la mor-

\footnotetext{
45 Ver: Montilla Salas, X.; Sureda Garcia, B. (2008), La gota de llet: protecció a la infància i educació social a la Menorca contemporània, Maó, Institut Menorquí d'Estudis.

46 Alabern, E. (1921), Sobre la lactancia artificial en las Instituciones de Puericultura y en la Práctica Privada, Palma, Tipografía de Amengual y Muntaner, p. 13-14.

47 AlABERn, E. (1921), p. 75.

48 Alabern, E. (1921), p. 41.
} 
talidad que se había observado en este tipo de instituciones desde su implantación. No obstante, el médico Cerdá despreciaba el uso del biberón, no tanto por sus inconvenientes higiénicos ${ }^{49} \operatorname{como}^{\text {porque: }}$

«[...] en la mayor parte de los alimentos que con él se administran son farináceos, no contienen más que fécula, siendo insuficientes para la alimentación, pues no se halla en ellos elemento alguno nitrogenado; además [...] la saliva de los niños no tiene la propiedad de digerir los feculentos, explicándose de este modo los trastornos intestinales que lleva a la mayoría de estos pequeñuelos al sepulcro; trastornos que se desarrollan especialmente en verano $[\ldots] »^{50}$.

Por lo tanto la lactancia artificial sólo se justificó por prescripción médica y bajo su control en instituciones como las Gotas de Leche - que se tratarán más adelante- como parte de las campañas puericultoras. Por lo que respecta a la lactancia mercenaria sólo se entendía en caso de ausencia o muerte de la madre o por la existencia de algún tipo de problema físico o de enfermedad que imposibilitase este proceso fisiológico de la madre. Pero en el caso de los expósitos esta lactancia quedaba totalmente argumentada por lo que el sistema de crianza de las Inclusas se fundamentó en el uso de nodrizas tanto internas como externas. No obstante, las amas privadas eran duramente criticadas ya que según los médicos sólo tenían la pretensión de «[...] ganar dinero; poco le importa todo lo demás; ella sabe que la leche es mala, pero el egoismo se sobrepone, verdad es que el médico puede reconocerlas, pero no siempre se prestan $[\ldots]\rangle^{51}$. Esta práctica no sólo fue criminalizada por el hecho que la nodriza comercializaba con su leche, sino que a su vez implicaba una negligencia en la crianza de su propio hijo. La clase médica también alertó que la nodriza podía ser fuente de transmisión de enfermedades. Por todo ello este colectivo clamó por la necesidad de regular este tipo de lactancia, «Aquí todos sabéis como abundan, pero es lástima que al menos no estén reglamentadas, y se evitaría alguno de los muchos abusos que todos conocéis $»^{52}$. Aunque no fue hasta la primera ley de protección a la infancia (1904) cuando se reguló.

49 FILDES, V. (1988), The English wet - nurse and her role in infant care 1538 - 1800. Medical History, 32, pp. 142-173.

50 CERdà COLl, J. (1900), p. 19.

51 Mir MIR, J. (1906a), p. 11.

52 Mir MiR, J. (1906a), p. 12. 
b. Las campañas puericultoras y sus instituciones.

Las campañas puericultoras fueron iniciadas en España en 1902 con la abertura de las denominadas Gotas de Leche ${ }^{53}$. La Gota de Leche de la ciudad de Palma se inauguró en enero de 1907 bajo la dirección del médico Josep Mir Mir. Este médico inspirador de la institución local, ha dejado algunas conferencias relacionadas con el tema, como Los consultorios de niños de pecho y la gota de leche pronunciada en el Círculo de Obreros Católicos de la ciudad de Palma el 20 de junio de 1906. En este texto justificaba la utilidad de dichas instituciones porque servían para

«[...] imponer la Higiene como única ciencia capaz de prevenir ciertas enfermedades de la infancia, en particular su mayor enemigo, el verdadero Herodes de nuestros días, la guillotina de nuestro siglo, la diarrea.» ${ }^{54}$.

Las Gotas de Leche, entre otras funciones, consistían en un servicio de dispensa de leche, sin la pretensión de sustituir la lactancia materna ni tampoco relegar

«[...] la lactancia mercenaria, [sino que] facilita leche de la mejor calidad y convenientemente preparada, a aquellas madres que a juicio del médico no pueden amamantar a su hijo, por su secreción láctea insuficiente, por ser esta de mala calidad, o por carecer de ella en absoluto» ${ }^{55}$.

La leche despachada debía ser de vaca previamente tratada con agua, cloruro de sodio y azúcar, después filtrada, embotellada en biberones y esterilizada.

Los niños atendidos en estos consultorios eran convenientemente registrados en fichas individuales que contenían el nombre, la fecha de nacimiento, la edad de los padres, número de hermanos, antecedentes clínicos tanto propios como familiares y el peso. Medida que era actualizada semanalmente dada su gran importancia según el propio creador de la institución local: «El peso es el mejor guía que nos demuestra la salud del niño y su verdadero estado de

53 RODRíGUEZ OCAÑA, E. et al. (1985), Los consultorios de lactantes y gotas de leche en Espanya. Jano, XXIX, pp. 1066-1072 y RODRÍGUEZ OCAÑA (1998), p. 24.

54 MIR MIR, J. (1906b), Los consultorios de niños de pecho y la Gota de leche: objeo de la fundación, necesidad de su establecimiento, Palma, Tipografía de las hijas de Juan Colomar, p. 7.

55 MiR Mir, J. (1906b), pp. 9-10. 
nutrición; niño que no aumenta en peso, es niño enfermo» ${ }^{56}$. Éste, a su vez, era considerado un indicador de buena salud como rezaba la cartilla higiénica anteriormente citada. En caso de enfermedad estos niños eran visitados por un médico aunque si presentaban un cuadro infeccioso por sarampión, viruela o tosferina no podían acudir al consultorio para evitar el contagio a otros niños.

Otra gran función de los consultorios de niños de pecho fue la divulgación higiénico-sanitaria a través de las Escuelas de Madres a la cual debían asistir «[...] un día determinado de la semana todas las madres o encargadas de la lactancia de los niños, a la consulta que se hace en común, y en alta voz para que resulte más práctica con el ejemplo.» ${ }^{57}$. Los fondos económicos del consultorio se obtenían por suscripción popular en forma de socios protectores permanentes y de subvenciones del Ayuntamiento de la ciudad y de la Diputación Provincial.

Aún así en la ciudad de Palma desde 1895 existía la Sociedad de Protección a la Infancia organizada por el abogado y político mallorquín Alexandre Rosselló (1853-1923). Tenía la misma finalidad filantrópica de las Gotas de Leche. Su objeto era el de:

1. Procurar lactancia a los niños de familias pobres que no tengan derecho de ser atendidos por la Exma. Diputación provincial según lo dispuesto en el art. 5 del Reglamento de la Inclusa de Palma.

2. Proteger a los niños de toda clase y condición contra el abandono, la miseria, los malos tratamientos y los ejemplos de inmoralidad.

3. Fomentar la educación de la infancia por todos los medios que estén al alcance de la Sociedad.

4. Popularizar en las familias los preceptos más útiles, higiénicos y morales, en harmonía con los preceptos religiosos.

Nos enfrentamos, pues, a una institución que, aparentemente, sólo se ocupó de proporcionar ayuda a la lactancia, sin ningún tipo de atención sanitaria hacia los niños, lo que sí dispusieron las Gotas de Leche. La lactancia mercenaria con una duración de 18 meses fue la única que preconizó la Sociedad de Protección a la Infancia. El reclutamiento de las nodrizas se realizaba por una Comisión ejecutiva con el beneplácito de una Junta de señoras. Posiblemente la comisión contaba entre sus miembros con algún médico dado que una de sus potestades era la inspección de las nodrizas. Esta asociación sirvió para cubrir un espacio asistencial yermo, en un momento en que este tipo de servi-

56 MiR Mir, J. (1906b), p. 11.

57 Mir MiR, J. (1906b), p. 11. 
cios sólo se prestaban a la infancia abandonada por medio de las Inclusas. Pese a su carácter filantrópico, admitía lactancias de pago por dictamen de la anterior comisión. ${ }^{58}$

Sus estatutos también disponían la posibilidad de instalar asilos marítimos, salas-cunas, patronato de aprendices, hospitales, hospicios y escuelas. De todas estas iniciativas solo se ha podido documentar la existencia de asiloscunas a cargo de una congregación religiosa. En 1903 se inauguró el Asilo Cuna del Niño Jesús de carácter filantrópico auspiciado por Margalida Caimari de la asociación Obreras de San José. La justificación del asilo venía determinada por la incorporación de la mujer al mercado laboral, una mujer que también era madre, en una ciudad donde:

«[...] el número de madres jornaleras, a quienes el desempeño de los diversos oficios propios de la mujer, obliga a salir de sus casas para ganar el cotidiano jornal y sumando a estas las que concurren a fábricas y talleres, dan un crecido contingente de pobres madres puestas en el trance de abandonar sus hogares y por ende, á (sic) sus pequeñuelos, en los débiles brazos de niñas de pocos años, o hacinados en miserables, húmedas viviendas, encomendados á los mercenarios cuidados de alguna anciana de la vecindad». ${ }^{59}$

Este asilo ofrecía un servicio que no tenía parangón en la esfera pública. Al ser una asociación obrera no criminalizó a las trabajadoras, como sí pretendía el discurso médico, pero sí se la victimizó por las condiciones en que trabajaba, especialmente en el sector de la industria. Este asilo se localizó en uno de los barrios más populares de la ciudad en la calle Alfarería número 4. Tanto la Diputación Provincial como el Monte de Piedad y Caja de Ahorros de las Baleares contribuyeron a su sostenimiento económico y su gestión corrió a cargo de un patronato fundado a tal efecto.

En 1907 se fundó otro asilo de este tipo en el barrio de Santa Catalina. Su sostén económico en parte se debía a la cuota pagada por las madres, una peseta mensual. Este asilo contaba con un importante número de médicos protectores, muchos de los cuales ya se han citado como configuradores del discurso médico-social mallorquín. Entre ellos, Marià Aguiló, Tomàs Darder, Domingo Escafí, Josep Martí Ventosa, Antoni Mayol, Josep Mir Mir, Josep Mir Peña, Gabriel Oliver, Bernat Riera y Bernat Roca. Los médicos mallor-

58 Artículo $10^{\circ}$ del Reglamento de la Sociedad Protectora de la Infancia (1895), Palma, Escuela-Tipográfica Provincial.

59 Boletín de los Asilos Cuna del Niño Jesús de Palma y Santa Catalina: para acoger y cuidar durante el día niños en lactancia y párvulos pobres (1909), p. 3. 
quines recomendaban ardientemente estos asilos, que fueron creados a imagen y semejanza de la Créches francesas. Así el facultativo Marià Aguiló Cortès (1852-1924) ${ }^{60}$ en una alocución pronunciada en la Juventud Católica el 25 de marzo de 1883 manifestaba que este tipo de asilos permitían

«[...] proporcionar al hijo del obrero un aire puro, al propio tiempo que una alimentación sana, suficiente y apropiada a su edad, una temperatura constante, limpieza y cuidados no interrumpidos, como también dejar libre a la madre todo el tiempo que reclama su trabajo, y hacer que pueda entregarse a él con entera tranquilidad $[\ldots]\rangle^{61}$.

Para completar este apartado queda por mencionar como afectó localmente la promulgación de la primera ley de protección a la infancia de 1904, ley que desde hacía mucho tiempo anhelaba la clase médica mallorquina. Prueba de ello es que el Colegio Médico-Farmacéutico de la ciudad de Palma inauguró el año académico de 1904 con el discurso titulado Concepto higiénico-social de la protección de la infancia de Bernat Riera Alemany $\left(1874\right.$ - 1926) ${ }^{62}$. En este se exigía que la ley no se demorase por más tiempo y calificaba a Manuel Tolosa ${ }^{63}$, inspirador de la ley en España, de »[...] apóstol de la idea en España y, si no mienten los periódicos al anunciar tareas preparatorias

60 Licenciado por la Universitat de Barcelona en 1876. Fue uno de los médicos de la Inclusa. Impulsor de la creación del Colegio Médico-Farmacéutico y tuvo varios cargos relacionados con su revista. Fue presidente del Colegio de Médicos entre 1911 y 1912. Para más información ver: GRAN ENCICLOPÈDIA DE MALLORCA (1988-2004), volumen 1, pp. 40- 41; TOMÁS MONSERRAT (1985), p. 25.

61 Aguiló Cortès, M. (1903), Importancia de las Créches ó Casas-cunas: discurso leído en la Juventud Católica la noche del 25 de marzo de 1883, Palma, Tipografía de Felipe Guasp, p. 7.

62 Médico militar del Hospital Militar de Palma. Fue presidente de la Real Academia de Medicina de Baleares según aparece en la GrAN ENCICLOPÈDIA DE MALlORCA (1888-2004), volumen 14, p. 300.

63 La primera ley de protección a la infancia fue aprobada en España el 12 de agosto de 1904 gestada en el seno de la Sociedad Española de Higiene principalmente de la mano de Manuel Tolosa desde 1900 en un contexto favorable fruto del Congreso Internacional de Higiene y Demografía que se había celebrado en Madrid en 1898. Una de las principales conclusiones del congreso fue la necesidad de que leyes de este tipo debían ser promulgadas en toda Europa. Sobre el tema ver: Perdiguero E., Robles GonZÁlez, E. (2004), La protección a la infancia y la Sociedad Española de Higiene. En PERDIGUERo GIL, E. (comp.) Salvad al niño. Estudios sobre la protección a la infancia en la Europa mediterránea a comienzos del siglo XX, Valencia, Seminari d'Estudis sobre la Ciencia, pp. 93-120. 
del actual ministerio, quizás esté reservado á un mallorquín ilustre el llevarla á la práctica» ${ }^{64}$ refiriéndose al abogado y político Antoni Maura. Además en el discurso mostraba los beneficios que una ley semejante había producido en Francia. El autor presuponía que la ley debía corregir «[...] perniciosos errores de las costumbres» a más de impedir "[...] las inicuas usurpaciones a que se presta el abuso de las amas convertidas en materia de industria productiva. ${ }^{65}$.

La ley de protección de 1904 pretendía salvaguardar la salud física y moral de los menores de 15 años. Para ello y entre sus acometidos particulares se hallaba el de vigilar la lactancia mercenaria. Además debía prestar atención a las casas-cuna, los asilos, las escuelas, los talleres y a la institución benéfica por excelencia de la infancia abandonada, la Inclusa. Sus funciones fueron establecidas definitivamente mediante un reglamento publicado en 1908.

Si la publicación del reglamento de la ley ya había sufrido un considerable retraso en su disposición, más lo sufrió la constitución de las juntas locales de organización que la ley general había previsto. La Junta Provincial de Protección a la Infancia y Represión de la Mendicidad de las Baleares fue constituida definitivamente el 16 de marzo de 1911 por requerimiento de la Real Orden de 8 de febrero de 1911.66 Así en el acta de constitución se manifestó que "Ahora la situación de la Junta es distinta, cuenta con recursos propios y por lo tanto está llamada a tener mucha importancia realizando de una manera práctica la humanitaria misión que le está encomendada». ${ }^{67}$ Prueba de que con anterioridad la junta local ya había sido constituida. Las juntas locales fueron divididas en cinco secciones: Puericultura y Primera Infancia, Higiene y Educación Protectora, Mendicidad y Vagancia, Patronato y Corrección Paternal y como última sección la denominada, Jurídica y Legislativa.

La primera sección, Puericultura y Primera Infancia, relacionaba mensualmente el número de niños protegidos bajo su auspicio institucional. De

64 Riera Alemany, B. (1904), Concepto higiénico-social de la protección de la infancia, Palma, Tipografía de las hijas de Juan Colomar, p. 37.

65 Riera Alemany, B. (1904), p. 37.

66 La Real Orden de 8 de febrero de 1911 disponía en su primer artículo que: [...] se procederá por los Gobernadores y Alcaldes á constituir inmediatamente, si ya no lo estuvieran, las Juntas provinciales y locales de Protección á la Infancia y Represión de la Mendicidad, atendiéndose al efecto á los preceptos de la Ley de 12 de Agosto de 1904, Real Decreto de 24 de Enero de 1903 y Real orden del 28 de Febrero del mismo año. Gazeta de Madrid, $09 / 02 / 1911$.

67 Acta de Constitución de la Junta Provincial de Protección a la Infancia y Represión de la Medicidad de Baleares, 17/03/1911. Guía de la Junta Provincial de Protección a la Infancia y Represión de la Mendiciad (1911), Pro Infantia, Palma, Imprenta de Rotger. 
esta manera en el Boletín de Estadística Municipal de Palma se puede consultar el número de niños a quienes atendía la Gota de leche de Palma, además de los litros de leche despachados mes a mes.

Una vez expuesto el contenido de los discursos médicos relativos a la reforma sanitaria y al fomento de la lactancia materna se pueden observar al menos dos cuestiones que atañen directamente a lo planteado en un principio: la influencia de los profesionales de la salud en el descenso de la mortalidad y la consecución social que ayudó a convertir en intolerables las causas evitables de enfermedad y muerte. Prueba de ello son los bajos niveles de mortalidad en la infancia observados en la ciudad de Palma. Desde 1880-1890 la mortalidad infantil y juvenil se hallaba en franco retroceso mostrando valores del orden del $100 \%$ en las primeras décadas del siglo XX. ${ }^{68}$

Recibido: 29 de octubre de 2010

Aceptado: 25 de abril de 2011

\section{AGRADECIMIENTOS}

Me gustaría agradecer a mi directora de tesis, la Dra. Isabel Roll sus comentarios y a los evaluadores sus sugerencias, que han ayudado a mejorar este artículo.

68 Pujadas Mora, J. M. (2009). 